\title{
Sinopse do gênero Cobelura (Coleoptera, Cerambycidae, Lamiinae, Acanthocinini), com descrição de três espécies novas
}

\author{
Danielle C. Corbett
}

Museu Nacional, Universidade Federal do Rio de Janeiro, Quinta da Boa Vista, São Cristovão, 20940-040 Rio de Janeiro, RJ, Brasil (kafer@infolink.com.br).

\begin{abstract}
Synopsis of the genus Cobelura (Coleoptera, Cerambycidae, Lamiinae, Acanthocinini), with description of three new species. Eight species are considered for the genus Cobelura Erichson, 1847, three described herein: C. stockwelli sp. nov., from Panamá (Canal Zone, Darien), C. wappesi sp. nov., from Ecuador (Pichincha) and C. howdenorum sp. nov., from Colombia (Norte de Santander). The treatment of each new species includes information on its geographical distribution, photographs and a comparison with its most similar congenerics. A key to species of Cobelura is presented.
\end{abstract}

KEYWORDS. Cerambycidae, Acanthocinini, Cobelura, Neotropical region, taxonomy.

\section{INTRODUÇÃO}

O gênero neotropical Cobelura Erichson, 1847 foi originalmente proposto para Cobelura lorigera Erichson, 1847, do Peru oriental. Em 1984, MonNÉ apresentou revisão e chave de identificação para as cinco espécies então conhecidas: C. lorigera Erichson, 1847 (Peru, Junin: Satipo); C. vermicularis Kirsch, 1889 (Equador, Pichincha: Santo Domingo de los Colorados); $C$. peruviana (Aurivillius, 1920) (Peru, Junin: Satipo, Madre de Dios); C. claviger (Bates, 1885) (Panamá, Chiriquí: Bugaba; Costa Rica, Guanacaste: Golfito) e C. sergioi Monné, 1984 (Ecuador, Napo: Lago Agrio).

Os caracteres que possibilitam distinguir Cobelura dos outros gêneros de Acanthocinini são: antenas mais curtas ou pouco mais longas que o corpo; lados do protórax inermes; pronoto sem tubérculos; élitros sem setas e sem crista centro-basal; presença de carenas dorsais nos élitros e aspecto dos últimos segmentos abdominais (MonNÉ, 1984). O gênero tem distribuição nas Américas Central e do Sul, ocorrendo desde a Costa Rica até o Peru (Monné, 1995).

O material estudado pertence às coleções: American Coleoptera Museum, Bulverde, Texas, E.U.A. (ACMB); Canadian National Collection of Insects, Ontario, Ottawa, Canadá (CNCI); Museu Nacional, Universidade Federal do Rio de Janeiro, Rio de Janeiro, Brasil (MNRJ); Museu de Zoologia, Universidade de São Paulo, São Paulo, Brasil (MZSP); National Museum of Natural History, Washington, D.C., E.U.A. (USNM).

Chave para as espécies de Cobelura.

1. Élitros com faixas de pubescência branco-amarelada ou castanha.

Élitros sem faixas de pubescência branco-amarelada ou castanha

2(1). Élitros com faixa oblíqua pós-mediana de pubescência contrastante; pronoto sem faixa de pubescência branco-amarelada, ou com quatro faixas 3

Élitros sem faixa oblíqua pós-mediana de pubescência contrastante; pronoto e élitros com uma faixa de pubescência branco-amarelada ininterrupta em cada lado. Peru (Junin)

C. lorigera Erichson, 1847

3(2). Élitros com faixa oblíqua pós-mediana de pubescência branco-acinzentada ou brancoamarelada; lados do protórax arredondados, levemente estreitados antes da base ............... 4

Élitros com faixa oblíqua pós-mediana de pubescência castanho-escura; lados do protórax divergentes para trás. Costa Rica (Guanacaste) e Panamá (Chiriquí)

C. claviger (Bates, 1885)

4(3). Pronoto com quatro faixas de pubescência brancoamarelada (uma a cada lado do meio do pronoto, outras nas laterais); terço apical da sutura elitral coberto por faixa de pubescência brancoamarelada; tegumento de maneira geral castanhoescuro ou castanho-avermelhado, alaranjado no antenômero IV (fig. 2). Equador (Pichincha) ..... C. wappesi sp. nov.

Pronoto sem faixas; terço basal da sutura elitral coberto por densa pubescência esbranquiçada; tegumento de maneira geral preto, esbranquiçado nos dois terços basais dos antenômeros III e IV e em anel mediano no antenômero VI. Equador (Napo)

C. sergioi Monné, 1984

5(1). Élitros com máculas pequenas e arredondadas de pubescência esbranquiçada organizadas em fileiras longitudinais; antenômeros IV e VI sem anel esbranquiçado; carena dorsal longitudinal bastante evidente da base até o ápice dos élitros; pubescência de maneira geral amarelada (fig. 3). Colômbia (Norte de Santander)

C. howdenorum sp. nov.

Pronoto e élitros salpicados por abundantes máculas pequenas de pubescência branco- 
amarelada ou branco-acinzentada; anel esbranquiçado nos antenômeros IV e VI; carena dorsal longitudinal obsoleta, inicia pouco após a base dos élitros; pubescência predominantemente castanho-escura....

6(5). Élitros unicolores, castanho-avermelhados; lados do protórax subparalelos, não-estreitados antes da base; processo mesosternal em declive na borda anterior. Equador (Pichincha)

C. vermicularis Kirsch, 1889

Élitros pretos ou bicolores; lados do protórax arredondados, estreitados antes da base; processo mesosternal truncado 7

7(6). Escapo castanho-escuro no quinto apical; manchas irregulares de pubescência branco-amarelada (duas atrás dos lobos oculares superiores, outras no disco do pronoto), mais ou menos confluentes em duas faixas longitudinais no pronoto; élitros castanho-avermelhados na metade basal e castanho-escuros na apical (fig. 1). Panamá (Canal Zone, Darien) C. stockwelli sp. nov.

Escapo preto; manchas pequenas de pubescência branco-amarelada dispersas pelo disco do pronoto, não confluentes em faixas; élitros pretos. Peru (Junin)

C. peruviana (Aurivillius, 1920)

\section{Cobelura stockwelli sp. nov.} (Fig. 1)

Etimologia. O epíteto é uma homenagem ao Dr. Henry Stockwell (Smithsonian Tropical Research Institute).

c. Tegumento predominantemente castanhoavermelhado, alaranjado nas antenas e pernas; base dos fêmures amarelada. Tegumento castanho-escuro: cabeça; quinto apical do escapo; protórax; escutelo; metade apical dos élitros, junto à sutura; superfície ventral; extremidade apical dos fêmures e tíbias; extremidade basal das tíbias e tarsos. Tegumento esbranquiçado: anéis na metade basal do antenômero IV e nos dois terços medianos do antenômero VI. Pubescência de maneira geral castanhoescura. Pubescência branco-amarelada: borda posterior dos olhos; região posterior aos lobos oculares inferiores; mancha oblíqua atrás de cada lobo ocular superior; bases dos antenômeros II e III; anel mediano nos antenômeros IV e VI, podendo tê-lo também no VIII; máculas pequenas e irregulares no disco do pronoto (mais ou menos confluentes em uma faixa longitudinal a cada lado do disco, em continuidade com a mancha oblíqua atrás dos lobos oculares superiores); lados do pronoto; abundantes máculas no disco e margens dos élitros e nos lados do mesosterno e do metasterno; pernas (sendo a cobertura escassa nos fêmures e tíbias e densa nos tarsos); superfície ventral. Esta pubescência pode ser mais clara e esbranquiçada nos antenômeros e pernas.

Antenas alcançam os ápices dos élitros na extremidade do antenômero VI. Lados do protórax arredondados, levemente estreitados antes da base. Pronoto com pontos grandes, esparsos.

Ápices dos élitros obliquamente truncados; ângulos externos projetados em espinhos. Carena dorsal longitudinal inicia-se pouco atrás da base e alcança as extremidades. Superfície com pontos grandes, densos no disco, dispostos em fileiras longitudinais nos dois terços basais.

Processo prosternal com um quarto da largura de uma cavidade procoxal. Processo mesosternal truncado na borda anterior. Fêmures engrossados; metatíbias curvas. Últimos urotergito e urosternito emarginados.

૬. Antenas ultrapassam o ápice dos élitros no antenômero VII. Fêmures não-engrossados; metatíbias retas. Ovipositor apenas ultrapassa o ápice dos élitros; último urotergito aguçado; último urosternito truncado.

Dimensões em $\mathrm{mm}$, respectivamente, $\sigma^{1 /} / 9$. Comprimento total, 8,0-11,1/7,2-11,9; comprimento do protórax, 1,6-2,1/1,3-1,8; largura do protórax, 2,0-2,9/1,82,8; comprimento do élitro, 5,5-7,8/5,2-8,8; largura umeral, $2,3-3,8 / 2,4-4,1$.

Material-tipo: Holótipo ơ, PANAMÁ, Canal Zone: Barro Colorado Island $\left(9^{\circ} 9^{\prime} \mathrm{N}, 79^{\circ} 51^{\prime} \mathrm{W}\right), 18 . X I I .1996$, Pickering \& Windsor col. (USNM). Parátipos: đ', 3-10.II.1993 (MNRJ); 3

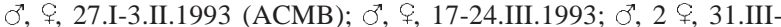
7.IV.1993; ๙, \&, 26.V-2.VI.1993; హ, 11-18.VIII.1993; ๙, 12-

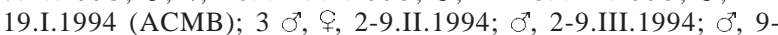
16.III.1994; ठ์, 23-30.III.1994 (MNRJ); \&, 11-18.V.1994 (ACMB); \&, 18-25.V.1994; \&, 15-22.VI.1994 (MNRJ); \&, 1522.VI.1994 (ACMB); ठ’, 11-18.I.1995 (ACMB); ठ', 28.XII.19944.I.1995 (MNRJ); क, 15-22.III.1995 (ACMB); 3 ơ, 22.II1.III.1995; đ', 12-19.IV.1995; $\&$, 10.I.1996 (MNRJ); \&, 10.I.1996 (MZSP); 2 హ, \&, 10.I.1996 (ACMB); \&, 1-8.II.1996 (ACMB); ठ’,

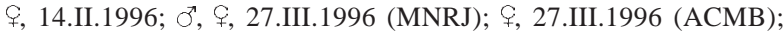
3 హ, \&, 10.IV.1996 (ACMB); ơ, f, 17.IV.1996; \&, 24.IV.1996

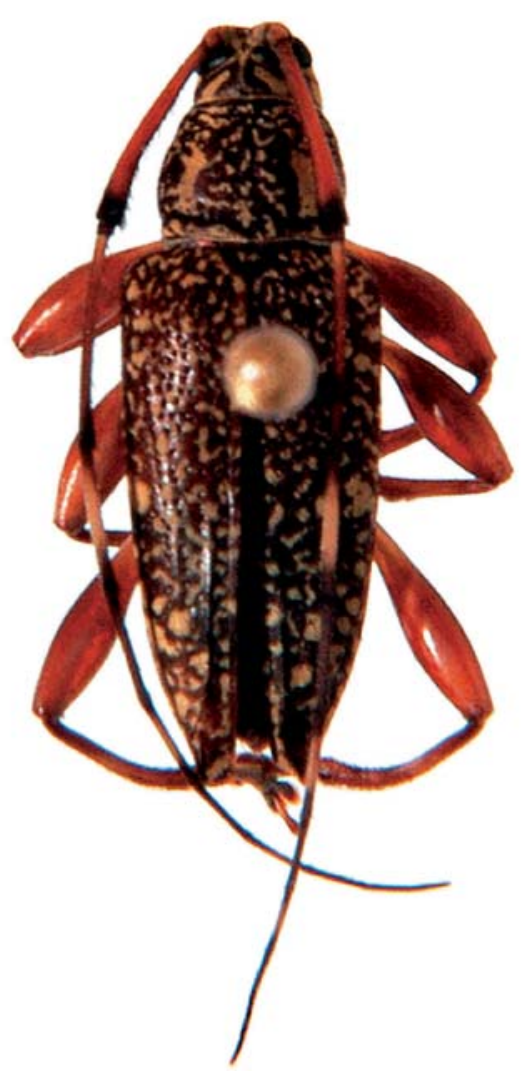

Fig.1. Cobelura stockwelli sp. nov., parátipo ơ, Barro Colorado Island, Canal Zone, Panamá, comprimento, 11,1 mm. 
(MZSP); ð゙, 29.V.1996 (MNRJ); ð゙, 29.V.1996 (ACMB); ð゙, 2.X.1996; đ', 20-27.XI.1996; び, 20-27.XI.1996 (MNRJ); ず, 23.X.1996 (MZSP); ơ, \&, 30.X-06.XI.1996 (ACMB); \&, 25.XII.1996 (MNRJ); đ, 1.I.1997 (MNRJ); హ, 4 ९, 1.I.1997

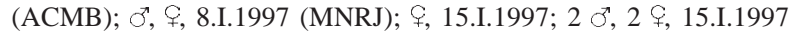
(ACMB); 2 \&, 22.I.1997; 2 ơ, §, 29.I.1997 ơ, \&, 5.II.1997 (MNRJ); đ, 5.II.1997 (MZSP); \&, 5.II.1997 (ACMB); 2 \&, 12.II.1997; \&, 19.II.1997 (MNRJ); 2 o', \&, 19.II.1997 (ACMB); \&, 26.II.1997 (MNRJ); đ', 12.III.1997; क, 12.III.1997 (ACMB); హ, 3 \&, 7.V.1997; ॐ, 21.V.1997; \&, 23.VII.1997; \&, 17.IX.1997 (ACMB); Darien: $18 \mathrm{~km}$ SE Ipeti (“along Darien Hwy”),, , 31.VIII.1979, Stockwell col. (ACMB).

Comentários. Cobelura stockwelli assemelha-se a C. peruviana e C. vermicularis por apresentar pronoto e élitros salpicados por abundantes máculas pequenas de pubescência branco-amarelada, sem faixas de pubescência esbranquiçada ou castanha, e pelos antenômeros IV e VI esbranquiçados. O ovipositor da fêmea nas três espécies não alcança ou apenas ultrapassa os ápices elitrais. Entretanto, as máculas em C. stockwelli são maiores e irregulares, mais ou menos confluentes em duas faixas longitudinais no pronoto e podem estar aglomeradas ou mesmo fundidas nas laterais dos élitros (na região mediana e no terço apical); antenas, nas fêmeas, ultrapassam os ápices elitrais no antenômero VII. Em C. peruviana e C. vermicularis: manchas bem pequenas, bem distribuídas pelo pronoto e pela superfície elitral; antenas das fêmeas não alcançam os ápices elitrais. C. stockwelli difere ainda das demais espécies pelo tegumento bicolor nos élitros, castanho-avermelhado na metade basal e castanho-escuro na metade apical, e por apresentar o quinto apical do escapo castanho-escuro.

\section{Cobelura wappesi sp. nov. (Fig. 2)}

Etimologia. O epíteto é uma homenagem ao Dr. James Wappes, que gentilmente enviou o material para identificação.

§. Tegumento de maneira geral castanhoavermelhado; mais escurecido na cabeça, protórax, escutelo e pernas anteriores e largamente nos ápices dos antenômeros, na face ventral da base dos fêmures e no terço apical das tíbias. Tegumento castanho-alaranjado nos élitros e na metade proximal do segmento IV das antenas. Pubescência predominantemente castanhoescura, entremeada por pilosidade amarelada na região basal dos élitros. Pubescência branco-amarelada: órbita dos olhos; sexto basal do antenômero III e terço proximal do antenômero IV; quatro faixas longitudinais que começam atrás dos lobos superiores dos olhos e continuam por todo o pronoto (as mais estreitas e recurvas, uma a cada lado do meio do pronoto, terminam na margem basal dos élitros; as duas mais largas e manifestas estendem-se pelos lados do pronoto e dos élitros até alcançar os ápices). Nos élitros, cada faixa emite um prolongamento submediano oblíquo descendente em direção à sutura, que segue junto desta até pouco antes do ápice elitral, onde se afasta e se funde novamente com a faixa lateral e ocupa pequena extensão no ápice. Entre a faixa lateral e o ramo oblíquo no terço apical dos élitros, encontram-se diversas máculas desta pubescência branco-amarelada, pequenas e de formato variado, algumas fundindo-se em manchas maiores ou em linhas longitudinais curtas e irregulares. Pode haver ainda, em cada lado do pronoto, uma terceira faixa longitudinal menos definida, intermediária às outras duas faixas.

Antenas quase duas vezes o comprimento do corpo, alcançam o ápice dos élitros na extremidade do antenômero VI. Lados do protórax arredondados, levemente estreitados antes da base. Pronoto com pontos esparsos.

Élitros com o ápice obliquamente truncado; ângulos externos projetados em espinhos aguçados. Superfície elitral com carena dorsal evidente da base até quase o ápice; pontos grandes, densos e profundos dispostos em fileiras longitudinais nos dois terços basais.

Processo prosternal com um terço da largura de uma cavidade procoxal. Processo mesosternal truncado na borda anterior. Fêmures não-engrossados; metatíbias curvas. Últimos urotergito e urosternito emarginados.

६. Antenas alcançam o ápice dos élitros; fêmures não-engrossados; metatíbias retas. Ovipositor ultrapassa cerca de 7,0 $\mathrm{mm}$ a ponta dos élitros; último urotergito aguçado; último urosternito truncado.

Dimensões em $\mathrm{mm}$, respectivamente, $\sigma / 6$. Comprimento total, 9,7/11,1; comprimento do protórax, $1,8 / 2,1$; largura do protórax, 2,2/2,6; comprimento do élitro, 6,9/8,0; largura umeral, 3,1/3,7.

Material-tipo. Holótipo ơ, EQUADOR, Pichincha: Puerto Quito, XII.1981, (sem nome de coletor) (MNRJ). Parátipo \&, Santo Domingo de los Colorados, VI.1985, G. Onore col. (MNRJ).

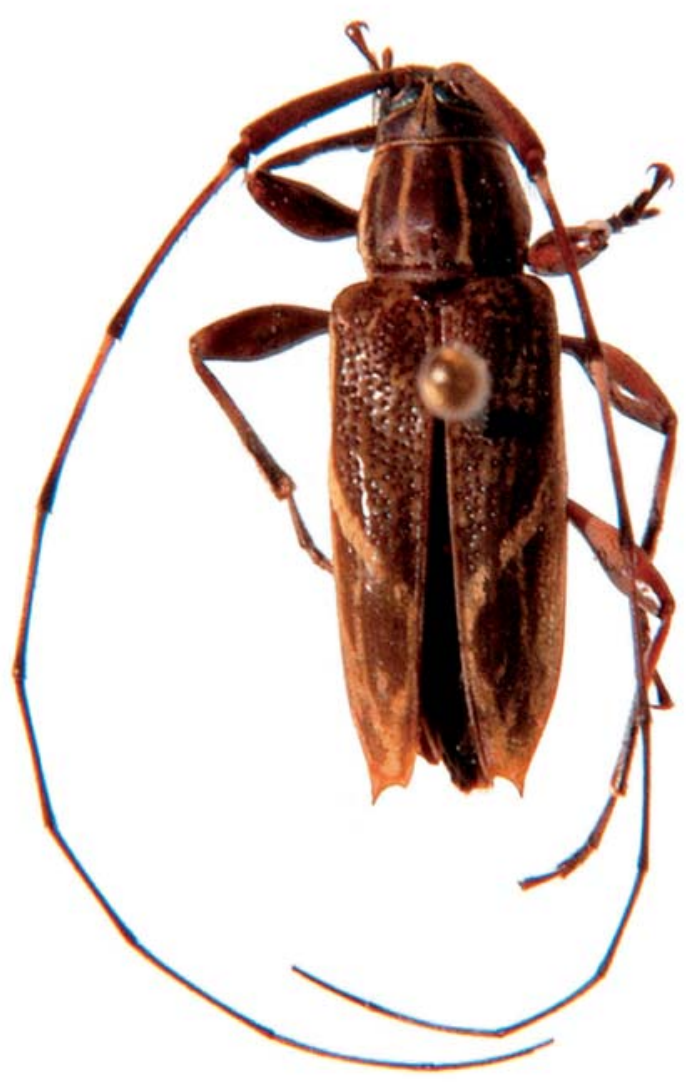

Fig. 2. Cobelura wappesi sp. nov., holótipo ơ, Puerto Quito, Pichincha, Equador, comprimento, 9,7 mm. 
Comentários. O padrão de faixas de pubescência brancoamarelada no pronoto e nos élitros permitem reconhecer prontamente $C$. wappesi. Nesta espécie, além das faixas ininterruptas nas laterais do pronoto e dos élitros, semelhantes às de $C$. lorigera, há mais duas faixas no pronoto, uma a cada lado do meio, e outras duas faixas oblíquas pós-medianas nos élitros, que se encontram e percorrem a sutura elitral até o ápice. Além disso, $C$. wappesi destaca-se por: antenômero IV alaranjado (nas outras espécies, este antenômero tem área esbranquiçada ou é castanho); antenas, nos machos, aproximadamente duas vezes o comprimento do corpo.

\section{Cobelura howdenorum sp. nov.} (Fig. 3)

Etimologia. O epíteto é uma homenagem aos Drs Anne e Henry Howden (Canadian Museum of Nature).

§. Tegumento de maneira geral castanho-alaranjado, mais claro nos élitros. Tegumento castanho-escuro: fêmures (os anteriores mais escuros); superfície ventral. Pubescência predominantemente amarelada, bastante densa (exceto junto às carenas dorsais). Pubescência esbranquiçada: máculas pequenas e arredondadas dispostas em cinco fileiras longitudinais em cada élitro,

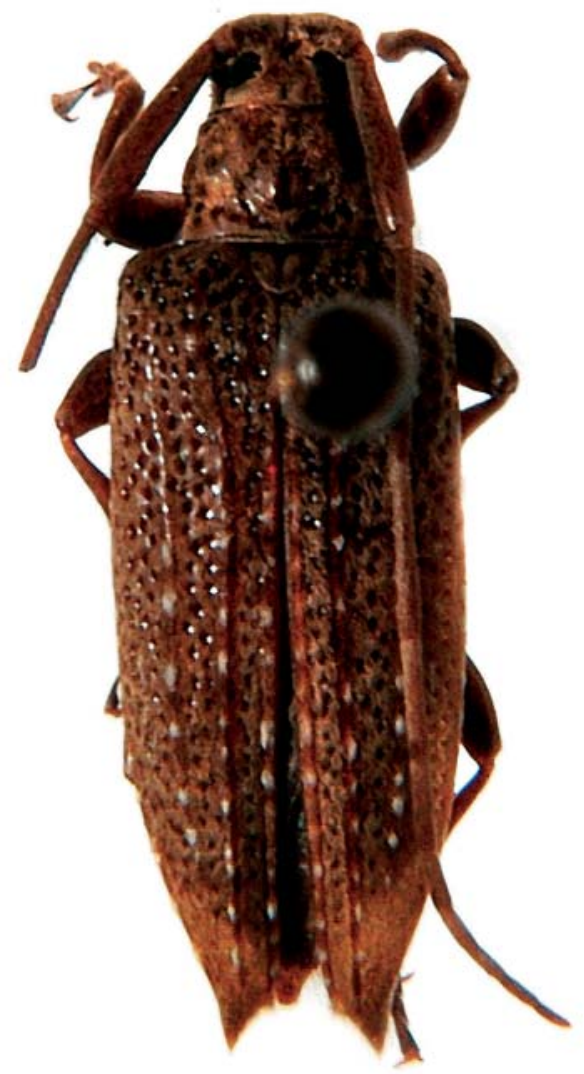

Fig. 3. Cobelura howdenorum sp. nov., holótipo $\Varangle$, Norte de Santander, Colômbia, comprimento, 9,5 $\mathrm{mm}$. sendo uma junto à sutura, duas fileiras coincidentes com as carenas dorsais (a interna mais longa que a externa) e duas na margem lateral do élitro (uma submedianamente, a outra mais externa).

Antenas alcançam o ápice dos élitros na extremidade do antenômero X. Protórax mais largo do que longo; lados arredondados, estreitados antes da base. Pronoto com superfície irregular, levemente deprimido no meio; pontos grandes, profundos e esparsos.

Élitros com ápice obliquamente truncado; ângulos externos projetados em espinhos agudos alongados. Superfície elitral com carena dorsal longitudinal evidente da base até as extremidades; pontos muito grandes e densos, dispostos em fileiras que se estendem até o ápice.

Processo prosternal com metade da largura de uma cavidade procoxal. Processo mesosternal truncado na borda anterior. Fêmures não-engrossados; metatíbias retas. Ovipositor não ultrapassa o ápice dos élitros; último urotergito arredondado; último urosternito truncado.

Dimensões em mm, \&. Comprimento total, 9,5; comprimento do protórax, 1,3; largura do protórax, 2,0; comprimento do élitro, 7,5; largura umeral, 3,1.

Material-tipo. Holótipo $\subsetneq$, COLÔMBIA, Norte de Santander: $25 \mathrm{~km}$ S Chinacota, 10.V.1974, H. \& A. Howden col. (CNCI).

Comentários. C. howdenorum difere de suas congêneres por não apresentar faixas de pubescência contrastante na superfície elitral, nem tê-la salpicada por abundantes máculas de pubescência amarelada ou acinzentada. Possui apenas pequenas manchas arredondadas de pubescência esbranquiçada organizadas em fileiras longitudinais, entremeadas na densa pubescência amarelada na superfície dos élitros. Distingue-se ainda por: superfície irregular e granulada do pronoto; ângulos externos do ápice dos élitros projetados em espinhos agudos muito alongados; carena dorsal desenvolvida, bastante evidente desde a base até a extremidade elitral; e coloração uniforme do tegumento em todos os antenômeros (a fêmea de $C$. claviger apresenta antenas com aspecto semelhante).

Agradecimentos. Ao Prof. Dr. Miguel A. Monné (MNRJ), pela orientação e revisão do manuscrito; ao Dr. James Wappes, pelo envio do material, e a Mauro M. Kury, pela execução das fotografias.

\section{REFERÊNCIAS BIBLIOGRÁFICAS}

Monné, M. A. 1984. Revisão do gênero Cobelura Erichson, 1847 (Coleoptera, Cerambycidae, Lamiinae, Acanthocinini). Revista Brasileira de Entomologia, São Paulo, 28(3):337-344.

1995. Catalogue of the Cerambycidae (Coleoptera) of the western hemisphere. Part XVIII. São Paulo, Sociedade Brasileira de Entomologia. 196 p. 